Columbia University in the City of New York

LAMONT GEOLOGICAL OBSERVATORY $\mathrm{CU}-2663-22$

PALISADES, NEW YORK

PESPONSE OF DYE TRACERS TO SEA SURPACE CONOITIONS

Report prepared by: B. Katz

R. Gerard

M. Costin

Technical Report No. CU-22-65 to the Atomie Energy Commission Contract AT(30-1)2663

June, 1965 



\title{
LAMONT GEOLOGICAL OBSERVATORY
}

(Columbia University)

Palisades, New York

\author{
Report prepared by: B. Katz \\ R. Gerard \\ M. Costin
}

Technical Report No. CU-22-65 to the Atomic Energy Commission Contract $\mathrm{AT}(30-1) 2663$

$$
\text { June, } 1965
$$

This publication is for technical information only and does not represent recommendations or conclusions of the sponsoring agencles. Reproduction of this document in whole or in part is permitted for any purpose of the U. S. Government.

In clting this manuscript in a bibliography, the reference should state that it is unpublished. 
Digitized by the Internet Archive in 2020 with funding from Columbia University Libraries 
ABSTRACT

Analysis of aerial photographs of a number of sea surface dye tracer experiments has revealed two features of the surface circulation: (I) a modified Ekman-type drift current, and (2) a system of helical current vortices having axes which are horizontal and nearly parallel to the wind. These data also indicate that there is a strong correlation between wind, sea state, and the development of a patch of dye. This suggests that such factors, rather than random eddies, may be of paramount importance to the spreading of a contaminant at the sea surface. 


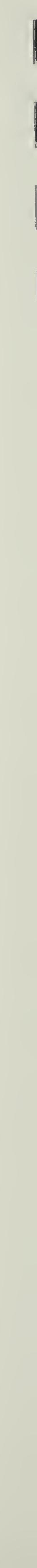




\section{INTRODUCTION}

Studies of turbulent diffusion and local circulation In harbors, estuaries and rivers have been facllitated in recent years by the use of fluorescent dye tracers (Pritchard and Carpenter, 1960). A program was begun at Lamont Geologlcal Observatory in 1960 to apply these techniques to the study of circulation, mixing and diffusion in the open ocean. Experiments have been made in a number of off-shore areas by introducing liquid rhodamine dye at the sea surface and measuring dye concentrations in the resulting dye patch with a sensitive fluorometer aboard an underway research vessel (Costin et al, 1963). In the early experiments dye was elther pumped onto the surface or simultaneously at many levels. More recently, dye releases have been made by dropplng 13-gallon plastic carboys fllled with liquid dye from the air. These dye "bombs" shatter upon impact with the surface, producing initially identical dye patches which closely approximate instantaneous point--source releases in the upper few meters.

Whenever possible, aerlal photographs of the dye patches have been taken to ald in the later analysis and construction of contours of dye concentration. These photographs were made using a 23-A Kodak Wratten filter (blocking wave lengths shorter than the emission spectrum of rhodamine dye, thus making the dye appear light in a dark background) with high speed black and white panchromatic fllm. For oblique photo- 


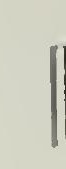


graphs a polaroid filter is also used. (For details see R. Iinfiela, 1964.)

More than 1300 vertical and oblique aerial photographs are avaliable for thirty-eight dye experiments made in various areas more than $8 \mathrm{~km}$. from shore and in depths exceeding 15 meters. Examination of these photographs discloses large-scale features common in varying degree to nearly all surface patches, which are not revealed in the analysis of the shipboard data.

In an attempt to organize these observations we have found that the main features of dye patch appearance and development may be arranged systematically with respect to wind speed and sea state. Table $I$ is the result of this synthesis anda, although preliminary, shows important relationships between the spread of a contaminant or artificial tracer and natural conditions at the sea surface.

\section{ELONGATION AND CURVATURE}

The most striking and recurrent features of ocean dye patterns are curvature and elongation. Thirty-two of the dye patches exhibited a marked tendency to elongate and to assume a comet-like appearance with curved tenuous talls. In all but two of these the direction of curvature from head to tail was cum sole. Figure 1 illustrates this characteristic pattern.

In waters that are shallow enough for bottom effects 



\section{Figure 1}

\section{Experiment of October 19, 1961, conducted in the New York Bight, $19 \mathrm{~km}$ from shore}

The ship has just completed a run down the long axis of the dye patch and can be seen on the right about to reenter. In 1ts passage through the patch it has stirred up dye in the tall portion on the left and clear water in the head portion on the right. The water depth was 60 meters and the wind speed $3 \mathrm{~m} / \mathrm{sec}$. 



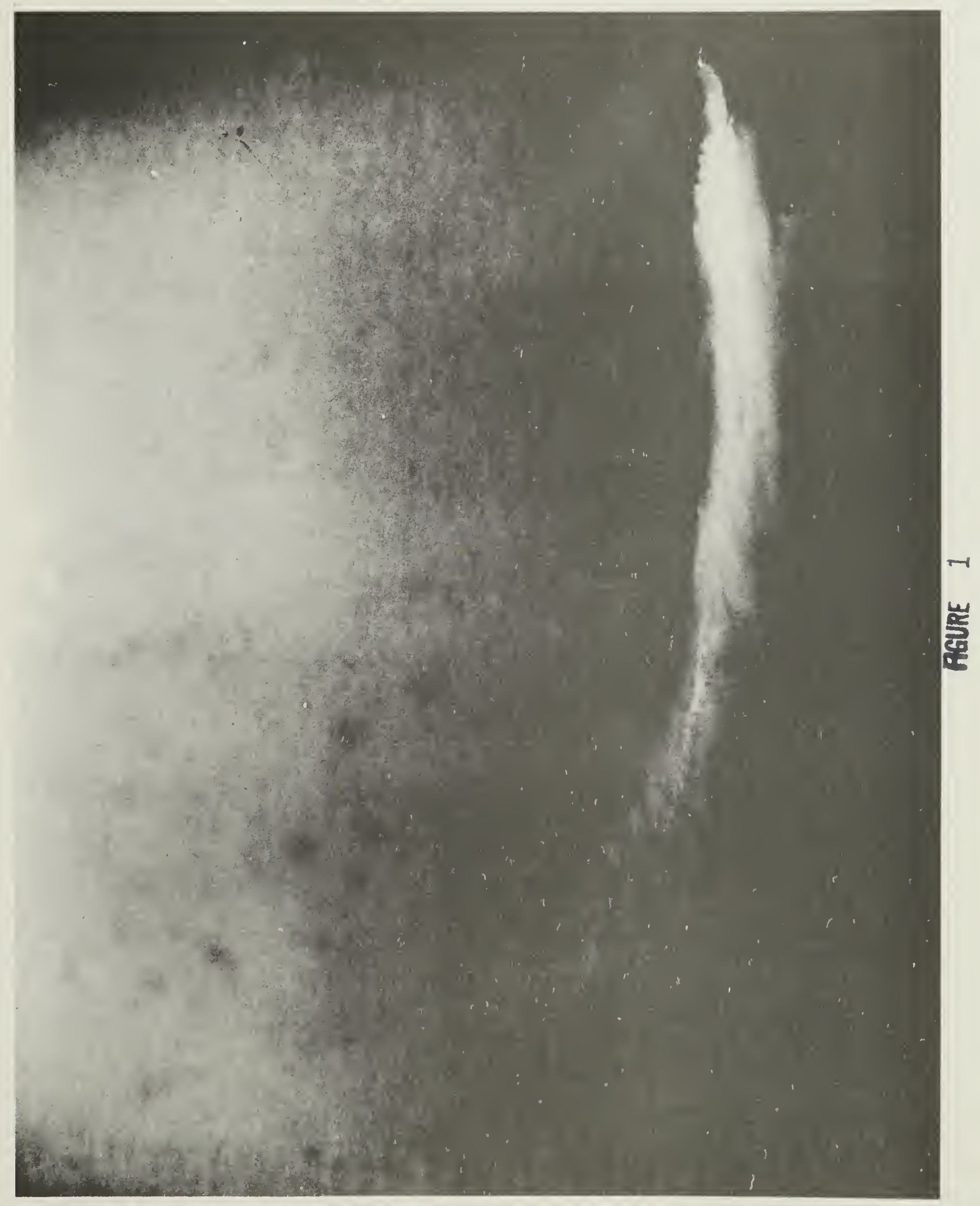



to appear at the surface, a clum sole rotatinc, tidal current could give rise to the type of curvature seen in the dye patches. In the ideal case, a curved tail resulting from rotary tidal current would begin to "shrink" after a halftidal cycle. Only one of the experiments has given any indication that this might have happened, while curvature has frequently been observed in water too deep (In one case, 900 meters) for bottom effects to influence the surface layers.

It can be shown that the depth of the layer of dyed water increases towards the more tenuous tall portion of the dye patch. This is illustrated in Figure 1 , where the ship (whose draft is approximately 3 meters) in its passage along the axis of the dye patch has stirred up dye in the tail portion on the left and clear water in the head portion on the right. This characteristic sloping distribution of the dye has also been observed by divers. These features suggest that the comet-like development of the dye patches is the result of shearing between horlzontal layers, in which each layer is moving slower and in a direction slightiy cum sole with respect to the layer above. Superficlally, this pattern resembles the classic Ekman spiral. Figure 2 shows how this type of current system would modify the shape of a vertical column of dye in a time interval from $T_{1}$ to $T_{2}$. If the cum sole curvature is the result of the Coriolis effect, the resulting pattenns of dye patches in the Southern Hemisphere should appear as mirror images of those in the 



\section{Figure 2}

An idealized model showing the way a classical Ekman-type drift current in the Northern Hemisphere would distort a column of dye which initially extended vertically downwards from the surface. 



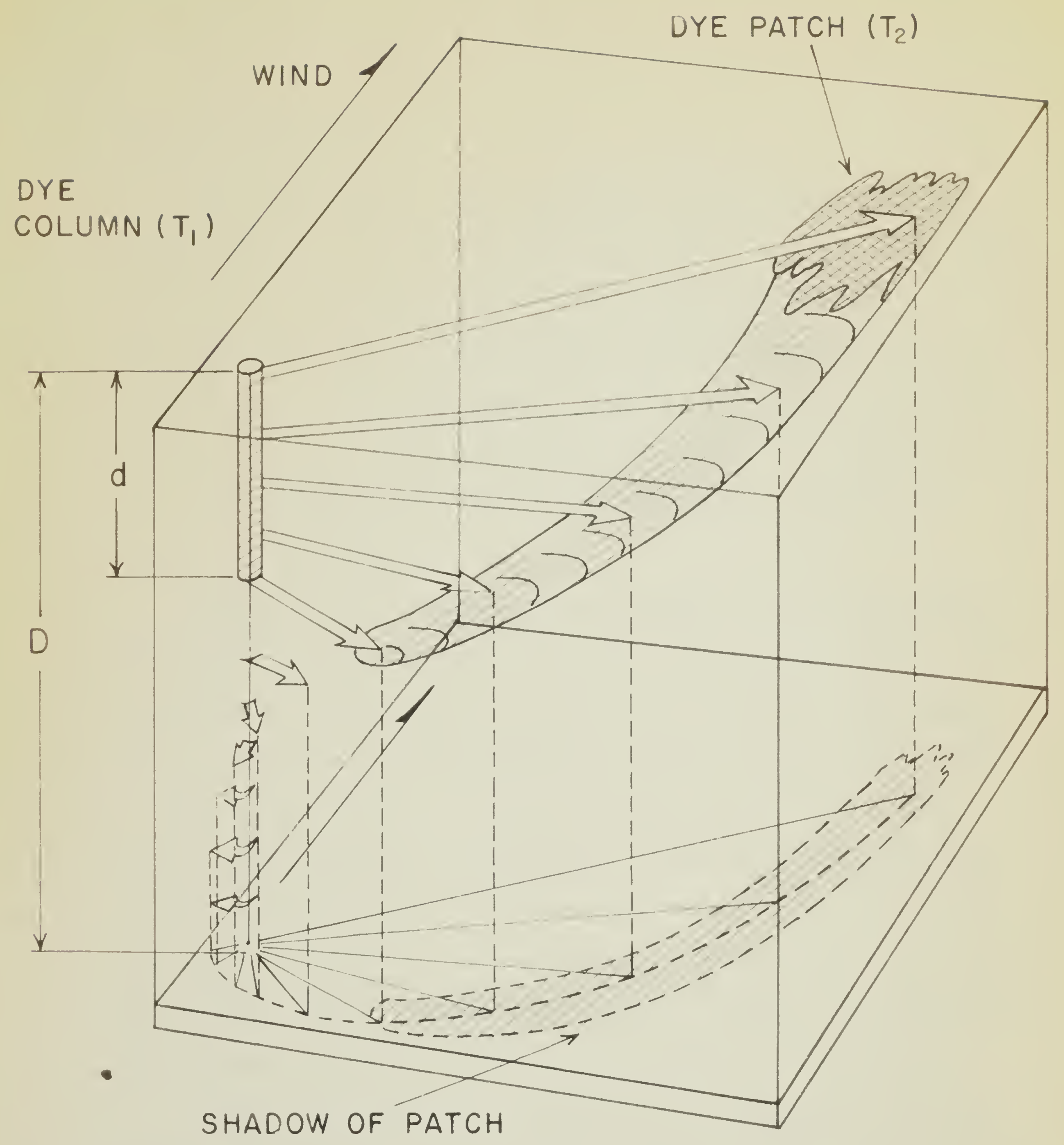

FIGURE 2 

Northern Hemisphere.

S1x experiments were conducted in the Southern Hem1sphere off the Argentine coast near Mar del Plata (Iatitude $38^{\circ} \mathrm{S}$ ) with the cooperation of the Hydropraphic Service of the Argentine Navy. Five of the resulting dye patches developed talls with cum sole curvature, whlle one developed no tall at all. In the latter case a tall was beginning to form, but stopped when the wind underwent an abrupt $90^{\circ}$ change in direction.

Figure 3 is a composite photograph of two dye patches oriented so that the wind direction (arrow) is common. The photograph on the left was made in the Northern Hemisphere and is typical of many experiments made off the east coast of the United States. The photograph on the right shows one of the Argentine experiments. From these observations there is little doubt that the dye curvature is related to the earth's rotation, as suggested by Gerard and Katz (1963) and Faller (1964). There 1s, however, great variability in the observed rate of elongation and degree of curvature.

Under the conditions imposed by an Ekman-type current system, a vertical column of dye would tend to elongate more rapidly than a patch restricted to the surface layers. Our experiments confirm that for a given set of conditions, when dye is introduced simultaneously at many levels, the rate of elongation is greater than in those cases where the dye is introduced at only one level at or below the surface. However, 



\section{Figure 3}

A composite photograph of two dye experiments

The one on the left was made near $40^{\circ}$ North latitude on May 5, 1964 in the New York B1ght, $16 \mathrm{~km}$ from shore in water 28 meters deep with wind of $4 \mathrm{~m} / \mathrm{sec}$; and that on the right was made near $38^{\circ}$ South latitude on July 27, 1964, $47 \mathrm{~km}$ off the Argentine coast in water 80 meters deep with wind of $5 \mathrm{~m} / \mathrm{sec}$. The arrow indicates wind direction. For these photographs the scales and the time after release of the dye are different. 



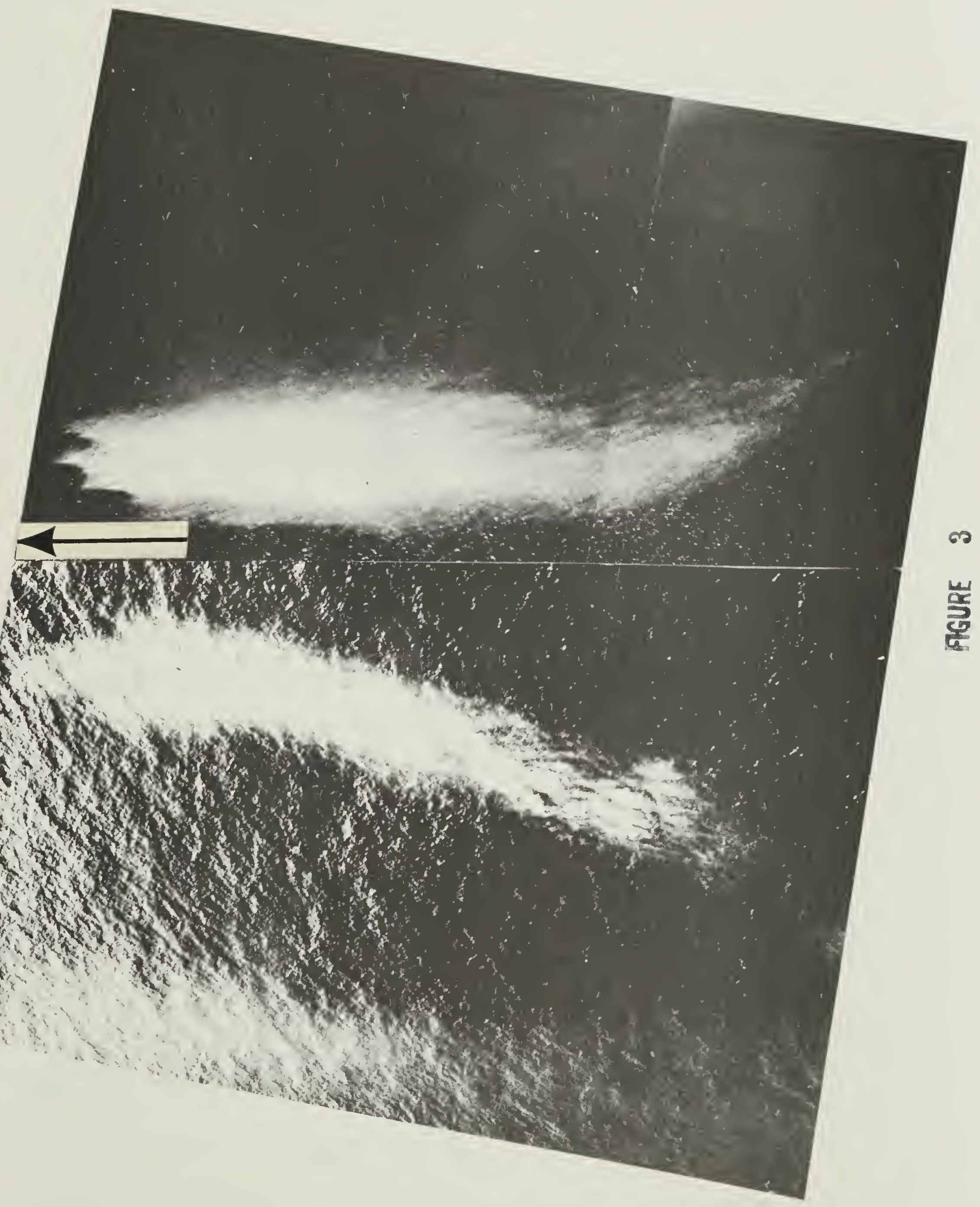



in a number of experiments where the depth and method of dye release were the same, the rate of elongation varied considerably. Some patches attained lengths of the order of a kllometer in about an hour, while others have taken three or four hours to reach lengths of a few hundred meters. According to Ekman's theory, the magnitude of the current at depth $z$ is given by:

$$
\begin{aligned}
& \left|v_{z}\right|=\left|v_{s}\right| \exp \left(-\frac{\pi}{D} z\right) \\
& D=\pi \sqrt{\frac{2 N z}{f}}
\end{aligned}
$$

where $\left|v_{s}\right|$ is the magnitude of the surface current; $f=2 \mathrm{w}$ sin is the Coriolis parameter; and $\mathrm{N}_{Z}$, the vertical eddy viscosity, is a measure of the efficiency of vertical momentum exchange. $D$ has the dimensions of a length and turns out to be the depth at which $v_{D}$ is directed opposite to $v_{S}$ and where:

$$
\left|v_{D}\right|=e^{-\lambda}\left|v_{S}\right|=0.043\left|v_{S}\right| \text {. }
$$

$D$ is thus considered to be the depth of penetration of the wind-induced current.

The difference in magnitude between the surface current and the current at depth $\mathrm{z}$ can be written:

$$
q(z)=\left|v_{s}\right|\left[I-\exp \left(-\sqrt{\frac{f}{2 N_{z}}} z\right)\right] \text {. }
$$

Since $D$ increases and $q(z)$ decreases with increasing $N_{z}$, we can see that increased vertical turbulence has the effect of spreading the Ekman spiral through a greater depth. Thus, 

according to Ekman's model, the rate of elongation should depend on both the wind speed and the efficiency of vertical exchange of momentum, which in the surface layers depends primarily on the wind and waves. Analysis of our data indicates that, under conditions of moderate winds and light seas, the dye resides in the upper few meters and long curved talls develop quickly, whereas under rougher conditions talls develop either slowly or not at all. This suggests that, while increased wind and roughness causes greater shearlng stress at the surface and greater vertical penetration of the dye, both of which would tend to enhance elongation, they also cause a decrease in the vertical component of the velocity gradient which retards elongation. Of these two effects, the latter is more important.

The amount of curvature observed depends upon the ratio $d / D$, where $d$ is the depth to which the dye can be seen. $D$, and to some extent $d$, depend on $N_{z}$, which in the surface laye's is strongly influenced by the wind and waves. Thus, it might be expected that under similar conditions of wind, sea, and method of dye release, the amount of curvature should be about the same. In fact, the observed curvature varies greatly, from barely perceptible to an overall turning through nearly 90 degrees; although there seems to be a tendency towards greater curvature under calmer conditions. It is believed that these differences may be related to difference In the stratification of the water column and to differences 

in the way $\pi_{z}$ varies with depth. Ichiye (1964) has shown that for $\mathrm{N}_{z}$ decreasing exponentially with depth, the curvature will be greater near the surface.

Occaslonally, in the early stages of an experiment when the wind is slight (less than $5 \mathrm{~m} / \mathrm{sec}$ ) and the sea calm (Iess than state 2), dye patches exhibit a sharp cum sole bend between the head portion and the tail portion. This bend frequentIy coincides with a line of discontinuity across the dye patch in which the apparent concentration decreases sharply towards the tall. In such cases the head portion slowly elongates parallel to the wind but exhibits no curvature, while the tail portion elongates more rapidly and curves slightly. It is evident from the photographs that the dyed water comprising the tail is sheared from the bottom of the head portion, whose depth is on the order of one meter. Figure 4 shows such a boundary condition at an early stage, one hour after release of the dye.

Ekman (1927) noted that certain data. In the atmosphere could be better reconciled with theory by disregarding the lowest few meters of air in which the eddy viscosity is considered to be much reduced and by assuming a uniform eddy viscosity over a fictitious ground which is in motion. In other words that the classical Ekman layer slips over a thin layer in which the change of velocity with height is proportional to the velocity, regardiess of the corlolis effect: and the velocity immediately above this "skin layer" is in 

Figure 4

\author{
Experiment of October 17, 1961, \\ conducted in the New York Bight, \\ $13 \mathrm{~km}$ from shore in water 27 meters deep
}

The discontinuity between the head and tall portions of the dye patch is the curved line separating the large, high concentration region on the left from the small, more tenuous tall on the right. The tall eventually grew to be nearly twice as long as the head. This photograph was taken one hour after release of the dye. 



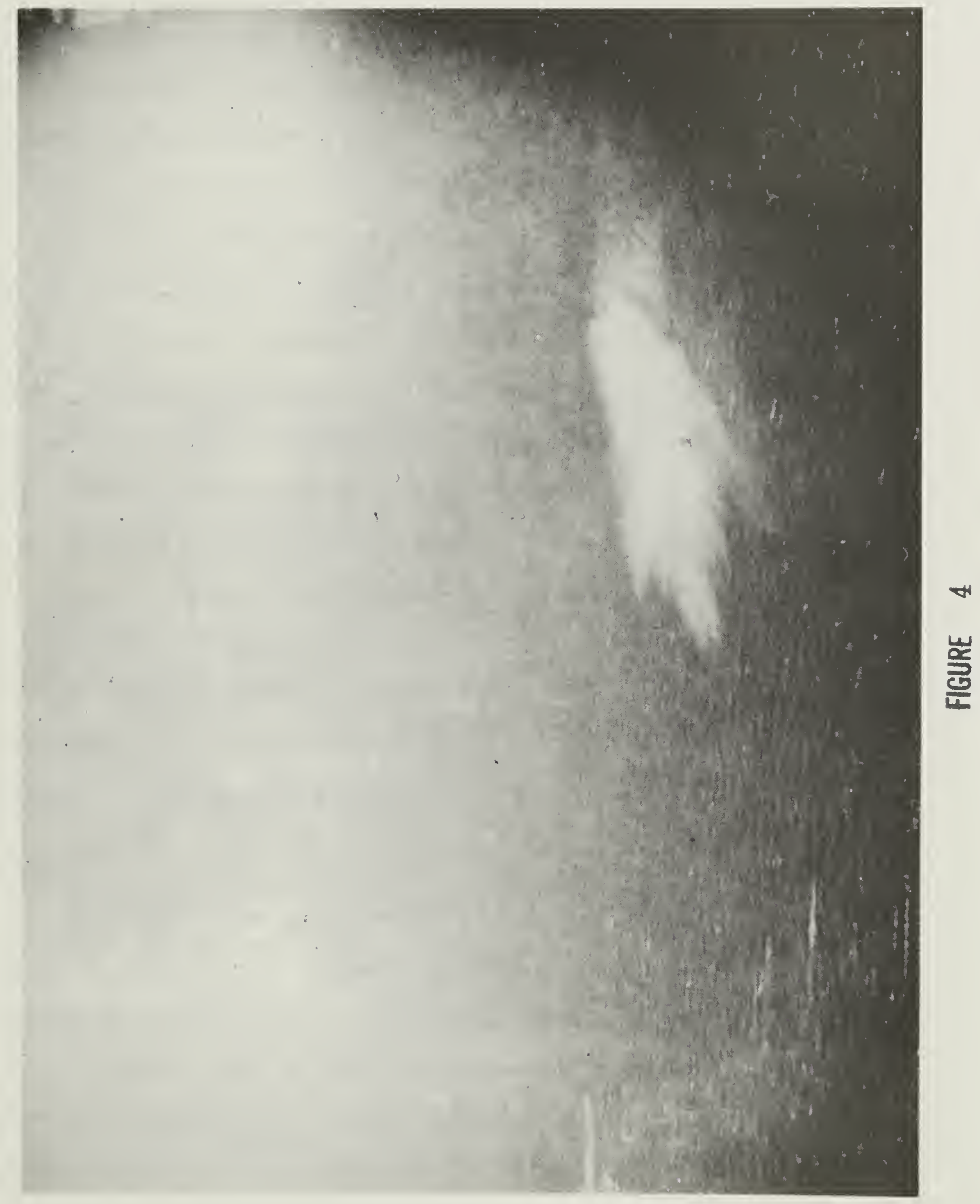



the same direction as the stress at that level. He further proposed that simllar skin layers also exist at the sea bottom and on either side of the a1r-sea interface.

The discontinuity zones seen in the dye patch photographs with their associated sharp bends could be explained by a similar assumption, if the skin layer were turbulent (1.e. having a very high vertical eddy viscosity so that the shear in this layer is much reduced). A body of dyed water moving within such a layer would exhibit no curvature and, because of the reduced shear, would elongate relatively slowly. The curved tall would result from dye which had penetrated below the skin layer into the uncerlying drift current (either during introduction or subsequently by diffusion) and would have the appearance of being sheared from the bottom of the head portion.

\section{RIBS}

Superposed on the form of a dye patch, there is frequently a pattern of parallel ribs allgned nearly parallel to the wind direction. Under high wind and sea-state conditions they protruce like fingers (Figure 5) and sometimes give the appearance of being arranged in two or more layers. It is rarely possible to trace an individual rib across the dye patch. When ribs appear under calm conditions, their withs and spacings are quite unfform: under rough conditions there is sone variability, but the widest is rarely as much as twice the widh of the narrowest. The width of the ribs 



\section{Fipure 5}

\section{Experiment of October 30, 1961, conducted in the New York Bight, $19 \mathrm{~km}$ from shore in water 60 meters deep}

The pattern typical of dye patches under moderate to rough seas and winds of $8 \mathrm{~m} / \mathrm{sec}$ or greater. The dye was released at 4 meters depth. The photograph was taken $11 / 2$ hours after release. About $1 / 2$ hour later a cum sole curved tail began to develop slowly, but it never achleved any great length. 



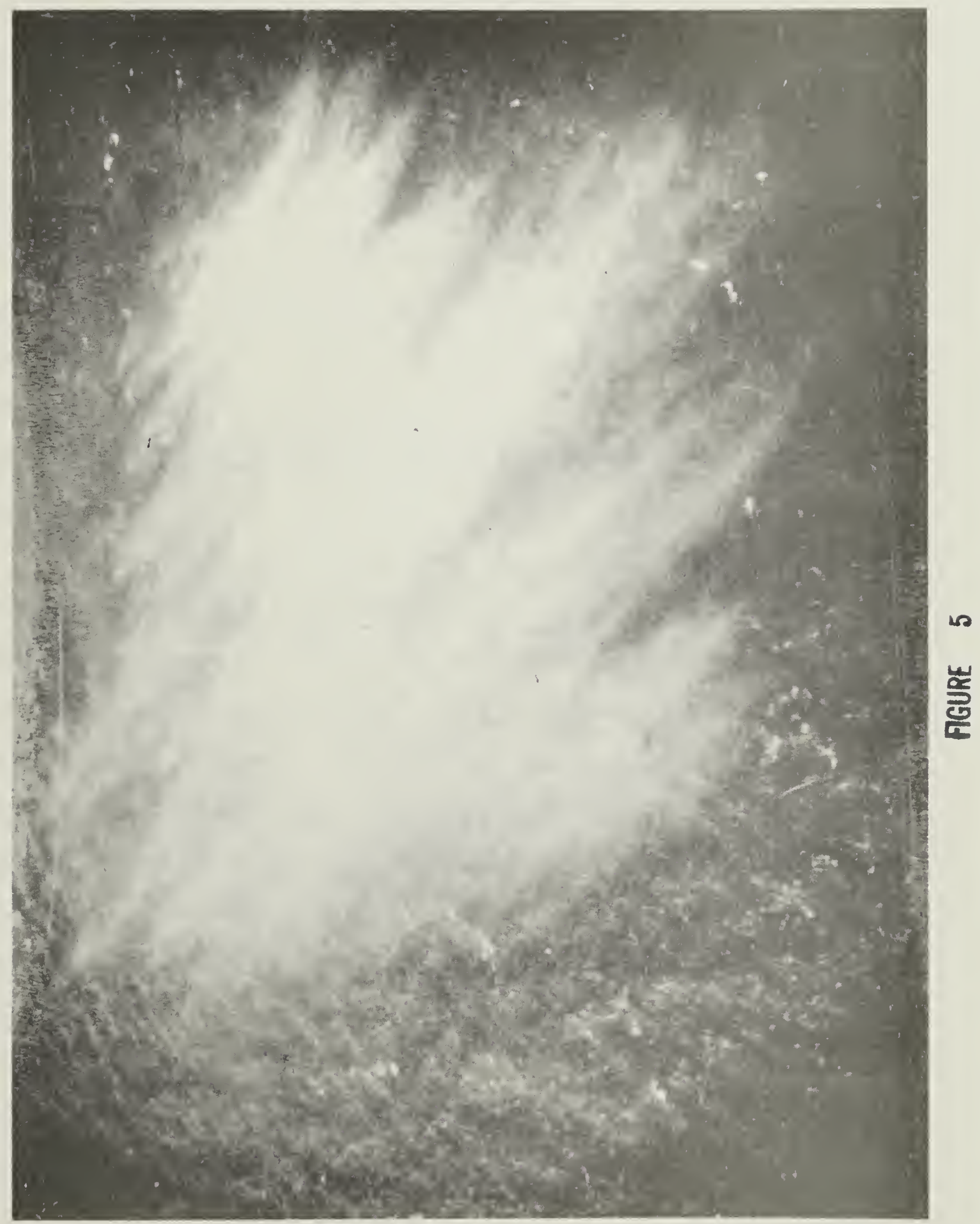



increases with greater wind speed and also appears to be related to the depth distribution of the dye. Figure 6 shows a number of observations of rib width plotted against wind speed. A curve from Faller and Woodcock (1964) is also plotted, representing the empirical relationship $(L=W \times 4.8 \mathrm{sec})$ between wind speed in meters per second (plotted in the Beaufort scale) and the spacing $L$ In meters of windrows of Sargassum observed on the sea surface.

In four of our experiments paper cards (used computer cards) were dropped near the dye patches. In all cases the cards moved away from the dye in the direction towards which the wind was blowing and at a greater speed than the dye. When dropped on the windward side of a dye patch, they moved through it. The cards always formed into parallel rows aligned with the dye patch ribs and with a spacing about the same as rib width. Faller (1964) has found that windrows are deflected slightly to the right of the wind, the average angle being $13 \pm 2.0$ degrees. In four out of six experiments where smoke generators were used on the sea surface to indicate wind direction, the dye ribs showed a similar angle.

There is evidence that the observed rib pattern shows a rapid response to changes in wind direction. This is 1Ilustrated by one experiment off the Argentine coast during which there was a change in wind direction of $70^{\circ}$ 

60

IYPE OF RELEASE

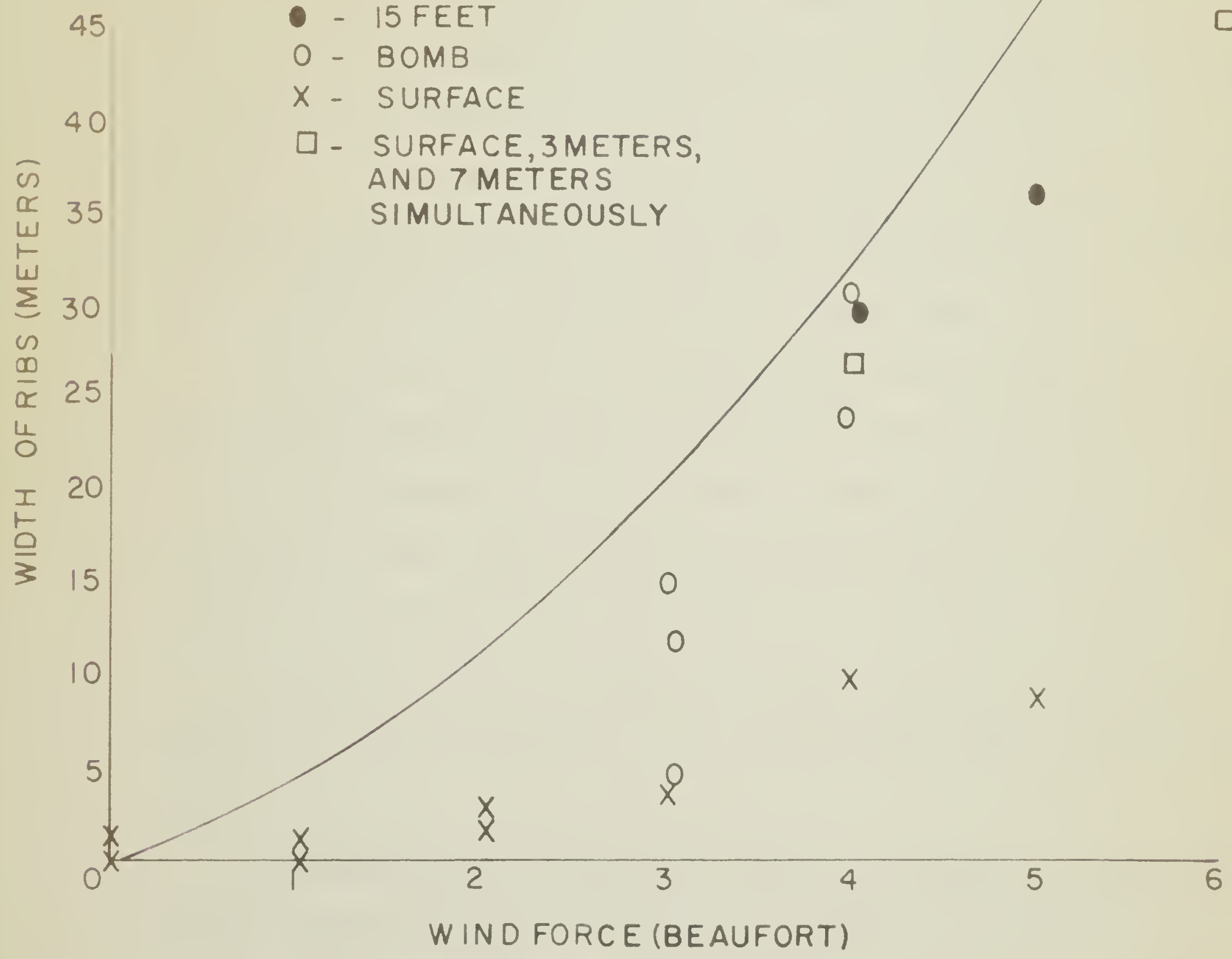

PGURE 6 
within a half hour, during which time the velocity remained constant at $5 \mathrm{~m} / \mathrm{sec}$. The initial rib pattern, consisting of three large ribs, was broken up during the wind change, and a larger number of smaller ribs developed, allgned with the new wind direction. Similar results have been observed in an experiment in the New York Blght.

While it is evident that the ribs align with the wind direction in the manner of windrows, the mechanism for this phenomenon is not fully understood. One suggested cause of the ribs is the rolling-up of water particles by wave action, as suggested by Costin et al (1963) and discussed by Ichiye et al (1964) with regard to work done by Hama (1962).

In a small number of experiments, in addition to ribs there have appeared bands in the dye patch which were different in character from the ribs. These bands were roughly parallel to the swell crests and were two to three times wider and less distinct than the ribs. Such bands appear to be caused by wave action; but since they occur at various angles to the rib pattern, the latter must have a different origin.

Langmu1r (1938) discussed surface streaks of floating debris and oil that were observed to line up parallel to the wind in numerous experiments at sea and on Lake George, New York. These respond quickly to large abrupt changes in wind direction, becoming realigned within a matter of minutes. He attributed these streaks to convergences caused 

by alternating left and right helical current vortices having horizontal axes parallel to the wind. The maximum velocity is in the direction of the wind and occurs on the surface in the convergences. Langmuir obtained results which indicate that the helical vortices extend down to the thermocline and that they are instrumental in its formation. Other observers (Stommel, 1951) suggest that they are confined to the top meter or less. Streaks of this type were also discussed by Hoodcock (1944), Dietz and LaFond (1950), Wellander (1953), and Ichiye (1964). The streaks range in width from several centimeters to several meters. The curve in Figure 6 gives the relationship between wind speed and windrow spacing found by Faller and Woodcock (1964), but not all observations reported by others fit the curve, possibly because there are usually smaller, less developed windrows between the more prominent ones.

Wellander (1963) and Ichiye (1964) Independently proposed a dynamic theory for the formation of cellular current structure by differential surface wind stress due to varlations in sea surface roughness. Faller (1964) Indicates that the cellular-type current structure might be the result of instability in the Ekman boundary layer, which he observed earlier in rotating tank experiments (Faller, 1963). The above-mentioned studies indicate that the wind will cause a cellular motion in the surface layers with align- 
ment parallel to the wind direction. Our results indicate that the rib pattern observed in dye experiments is a response to Langmuir vortices in a manner analagous to windrows.

\section{CONCLUSIONS}

The above discussion has dealt with the effects of ambient conditions on the spreading of a dye patch. Table I illustrates the results of an attempt to correlate dye patch development with wind speed and sea state in areas of sufficient depth and remoteness from the coast so that bottom and shoreline effects are negligible. The effects of method of release have been taken into account in compiling the table, but the possible effects of density stratiflcation have been onitted for the present, since these data are incomplete. In general, the table shows that, as the wind velocity and sea state increase, the rate of elongation decreases and the depth of penetration increases.

The fact that $90 \%$ of our results from various oceanic areas can be fitted into such a simple table indicates that the spreading of a contaminant at the sea surface is not a wholly random process, but is strongly influenced by amblent conditions. Experiments in very shallow or near-shore areas have not produced results consistent with Table I. of fourteen dye experiments made on the Bahama Banks, four have exhibited the ribbed features and none have developed curvature. It is expected that additional data will enable re- 


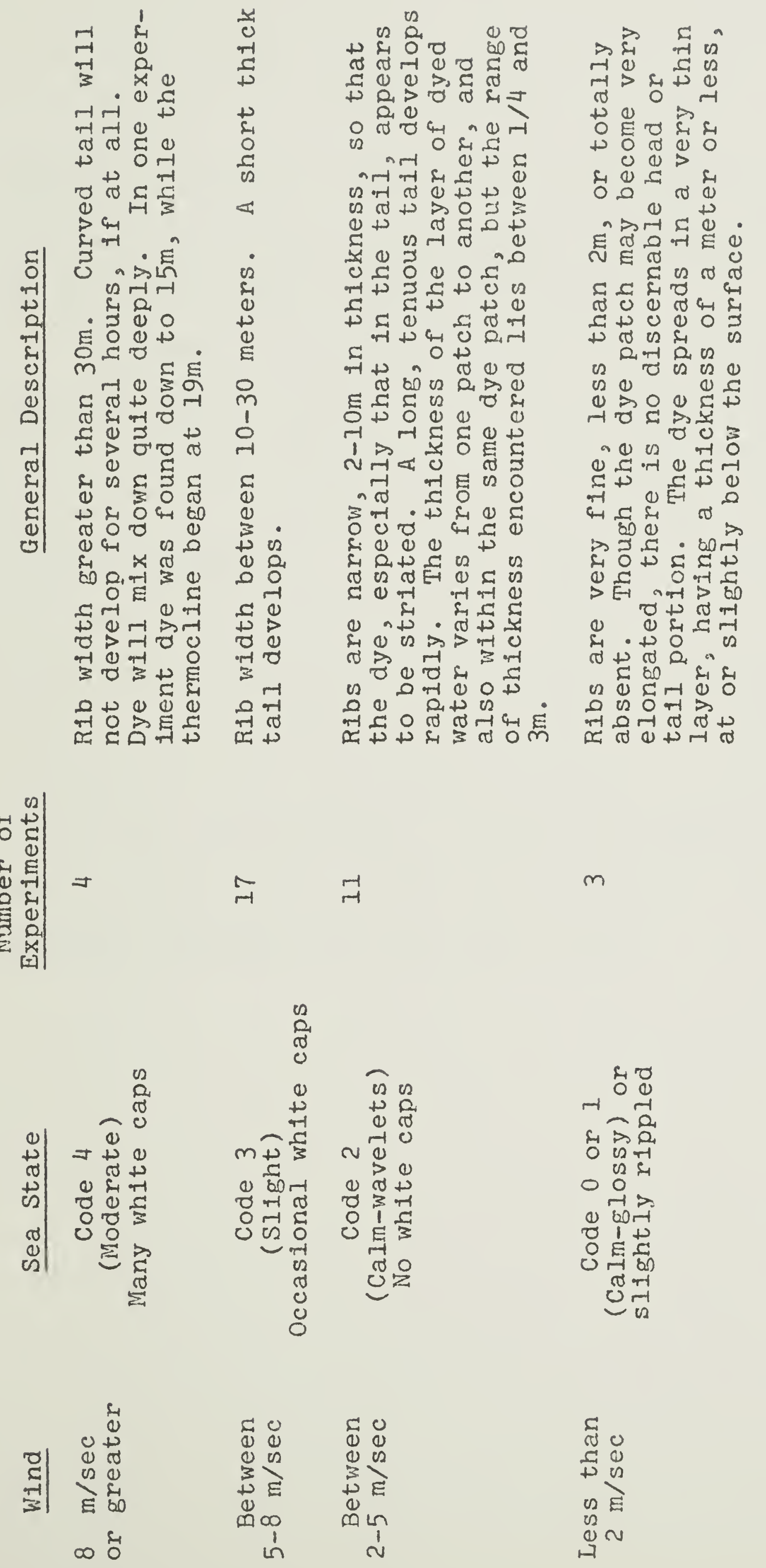


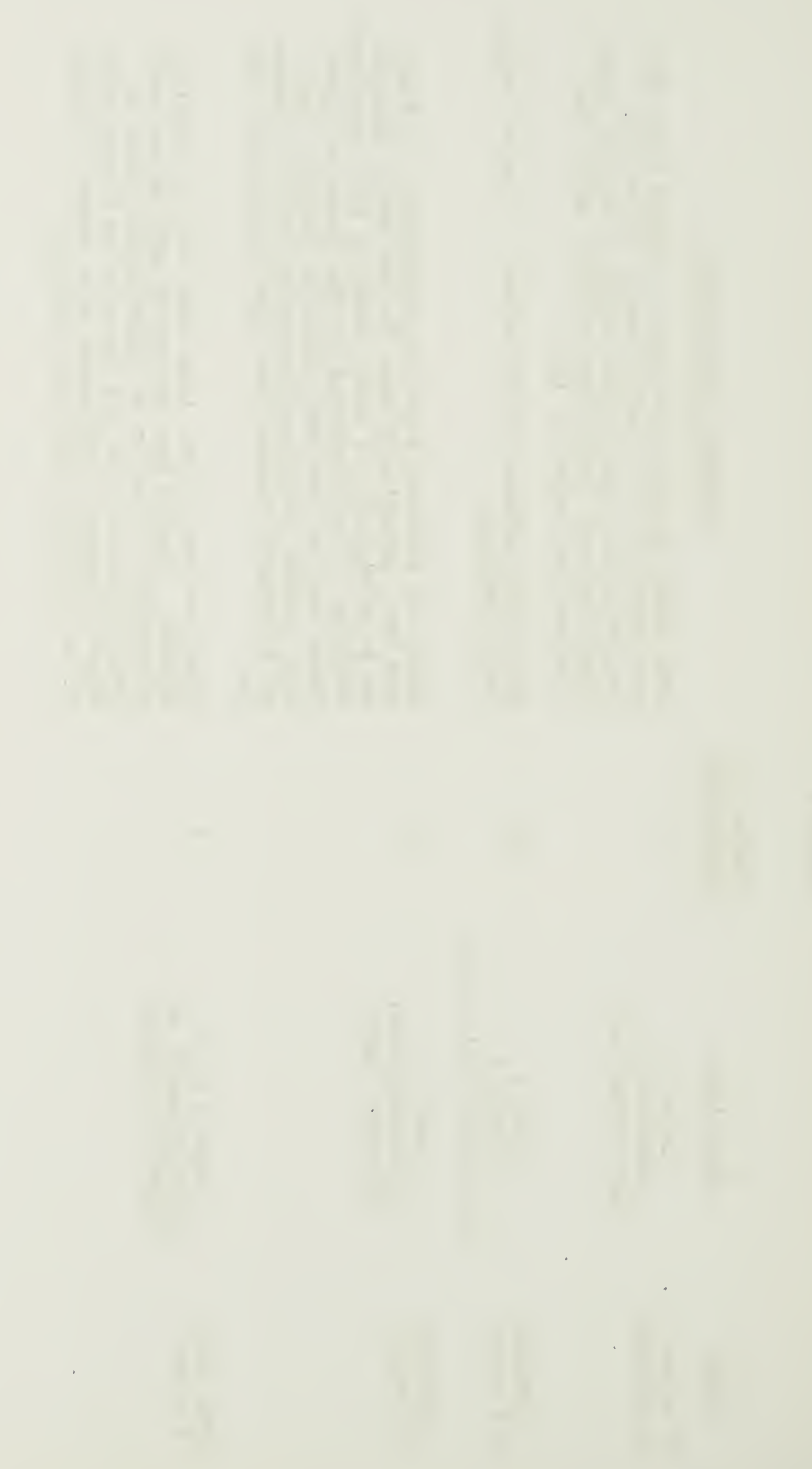


finements of Table I, which might be enlarged to include estimates of the rate of horizontal and vertical spread of the dye under widely varying conditions.

Our ability to predict the motion of any body of contaminated water in the sea will be determined by our knowledge of oceanic circulation. We have shown that, on a smaller scale, the spreading of this body will be influenced by local conditions. The rate of decay of the contaminant will then be dependent on this spreading and on diffusion by eddies much smaller than the patch of contaminant. It is believed that continued efforts to correlate the spreading and decay of artificial tracers to ambient conditions will further our understanding of oceanic circulation and, ultimately, enable us to predict the behavior of a fluid contaminant introduced into the sea surface. 



\section{ACKNOWLEDGMENTS}

The authors wish to express their gratitude to Dr. Takashi Ichiye and to Arnold Gordon for their advice, encouragement, and always constructive criticism. Thanks are also due to the Chesapeake Bay Institute of Johns Hopkins University for the use of some of their data.

A special debt of gratitude is owed to Capt. Luis Capurro and the Hydrographic Service of the Argentine Navy, whose cooperation and assistance made possible those experiments which were conducted in the Southern Hemisphere.

The work reported in this paper was supported by the Atomic Energy Commission of the U. S. Government under Contract AT(30-1)2663. 



\section{REP DENCES}

Costin, M., P. Dav1s, R. Gerard and B. Katz, 1963. Dye diffusion experiments in the New York Bight: Lamont Geol. Obs. Tech. Rep. \#CU-2663-2 (unpublished).

Dietz, R. S. and E. LaFond, 1950. Natural slicks on the ocean: J. Mar. Res. 9(2), 69.

Ekman, V. W., 1927. Eddy-viscosity and skin friction in the dynamics of winds and ocean currents: Memolrs, Roy. Met. Soc., II(20), 162-172.

Faller, A. J., 1963. An experimental study of instability of the lamina Ekman boundary layer: J. Flu1d Mech., 15(4), $560-576$.

Faller, A. J., 1964. The angle of windrows in the oceans: Telius XVI(3), 363-370.

Faller, A. J. and A. H. Woodcock, 1964. The spacing of windrows of sargassum in the ocean: J. Mar. Res., 22, 22-29.

Gerard, R. and B. Katz, 1963. A note on some observations of dye in coastal waters: Lamont Geol. Obs. Tech. Rep. \#CU-2663-3 (unpublished).

Hama, F. R., 1962. Streakline in a perturbed shear flow: Physics of Fluids $5(6), 644-650$. 

Ichiye, Takashi, 1964. On a dye diffusion experiment off Long Island: Lamont Geol. Obs. Tech. Rep. \#CU-2663-10 (unpublished).

Ichiye, T.: H. Iida and N. PIutchak, 1964. Analysis of diffusion of dye patches in the ocean: Lamont Geol. Obs. Tech. Rep. \#CU-2663-8 (unpublished).

Langmuir, I., 1938. Surface motion of water induced by wind: Science $87(2250)$, 119-123.

Linfield, R. W., 1964. Time and tide wait for Johns Hopkins, originally entitled Aerial photography of dye tracer experiments in the sea: Photo Methods for Industry, GellertWolfman Pub. Corp., New York.

Pritchard, D. H. and J. H. Carpenter, 1960. Measurements of turbulent diffusion in estuarine and inshore waters: Bull. of Intern'l Assn. Sci. Hyarol. 20, p. 37.

Stomme1, H., 1951. Streaks on natural water surfaces: Weather $17(3)$.

Welander, P., 1963. On the generation of wind streaks on the sea surface by action of surface films: Tellus X.V, p. $33-43$.

Woodcock, A. H., 1944. A theory of surface water motion deduced from the wind-induced motion of the physalia: J. Mar. Res. 5(3), p. 196-205. 



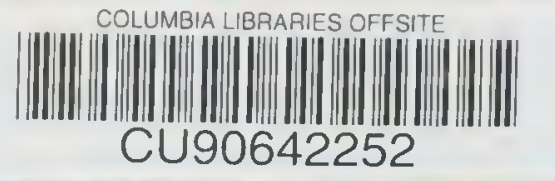


